PPPL-2802

PPPL-2802

UC-420, 421, 426

COMPARISON OF MEASURED ELECTRION DENSITY RISE AND CALCULATED NEUTRAL BEAM PARTICLE DEPOSITION IN THE TFTR TOKAMAK

BY

H. PARKET AL.

December 1991
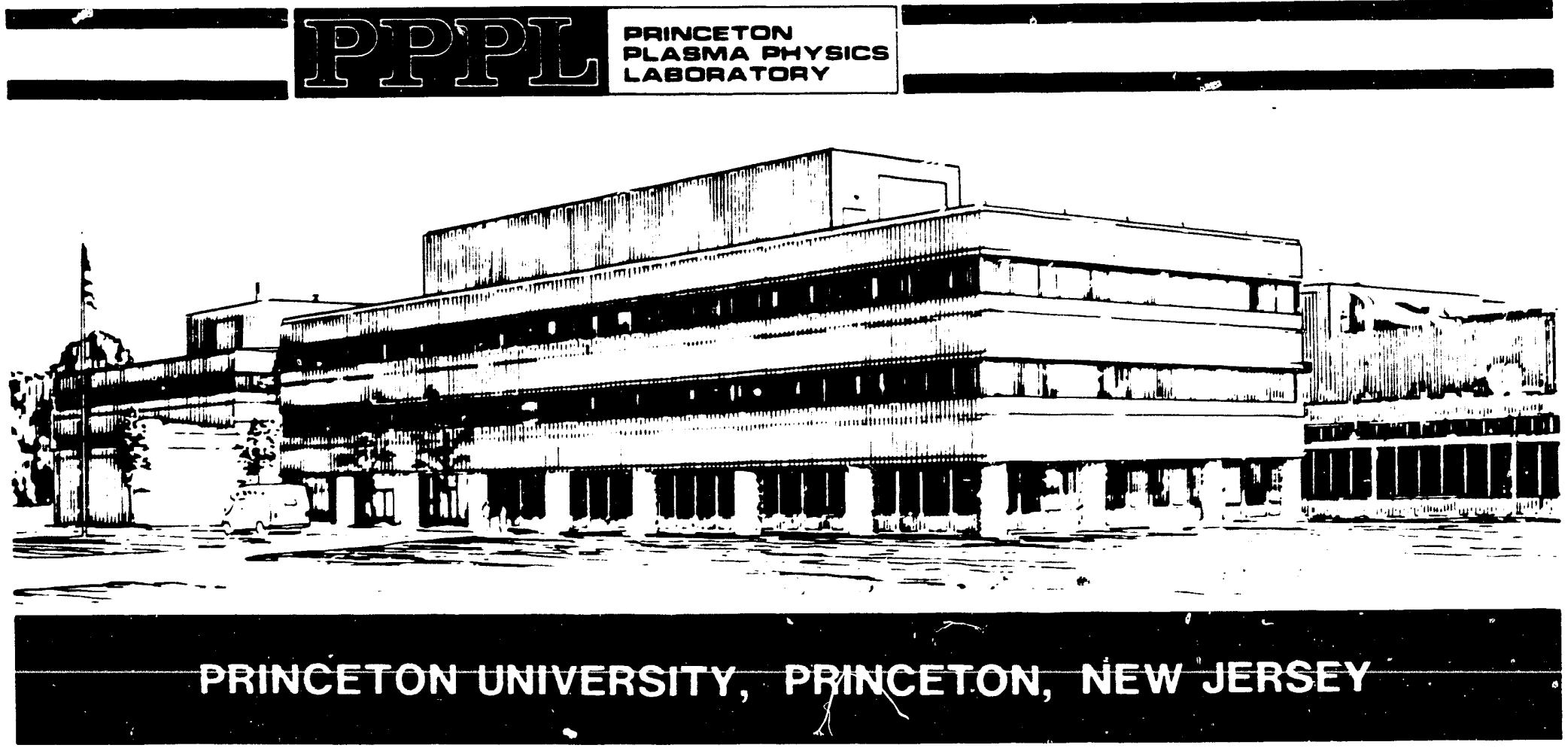


\section{NOTICE}

This report was prepared as an account of work sponsored by an agency of the United States Government. Neither the United States Government nor any agency thereof, nor any of their employees, makes any warranty, express or implied, or assumes any legal liability or responsibility for the accuracy, completeness, or usefulness of any information, apparatus, nroduct, or process disclosed, or represents that its use would not infringe privately owned rights. Reference herein to any specific commercial produce, process, or service by trade name, trademark, manufacturer, or otherwise, does not necessarily constituta or imply its endorsement, recommendation, or favoring by the United States Government or any agency thereof. The views and opinions of authors expressed !.erein do not necessarily state or reflect those of the United States Government or any agency thereof.

\section{NOTICE}

This report has been reproduced directly from the best available copy.

Available to DOE and DOE contractors from the:

Office of Scientific and Technical Information

P.O. Box 62

Oak Ridge, TN 37831 ;

Prices available from (615) 576-8401.

Available to the public from the:

National Technical Information Service

U.S. Department of Commerce

5285 Port Royal Road

Springfield, Virginia 22161

703-487-4650 


\title{
Comparison of Measured Electron Density Rise and Calculated Neutral Beam Particle Deposition in the TFTR Tokamak
}

\author{
H. K. Park, C. W. Barnes, R. Budny, \\ D. McCune, G. Taylor, and M. C. Zarnstorff \\ Princeton Plasma Physics Laboratory, \\ Princeton University, Princeton, NJ 08543
}

\begin{abstract}
The initial rate of rise of the central electron density during $\sim 100 \mathrm{kel}$ deuterium neutral beam injection is found to agree well with calculations of the beam deposition rate. The best agreement is with beam deposition calculations using older tabulations of the atomic cross-sections; the effects of using new tabulations or including multi-step ionization processes appear to approximately cancel. The neutral-beam deposition profile is a strong function of both the magnitude and the shape of the target plasma density. Peaked heating profiles can be achieved at high target densities inly from peaked target density profiles.
\end{abstract}

Los Alamos National Labriatory. Los Alamos. NM 
Precise information on the neutral-beam deposition profile is essential to the study of neutral-beam-heated tokamak plasmas, since the beam deposition profile provides the basis for understanding particle and heat transport experiments. It is also important to know how to create peaked deposition to optimize the effect of heating. In the past, the determination of the deposition profile primarily relied on computations. Recent studies $[1,2]$ have re-examined various atomic cross-sections and reported results which deviated from older measurements. $3-5$ In this paper, the measured rate of rise of the electron density in TFTR is compared to the calculated electron source rate from neutral-beam injection, $\left.S_{b e}(r, t)\right]$. The good agreement in the center of the discharge supports the use of the deposition calculations. and allows further comparison to different atomic cross-sections and processes. The shape of the beam deposition profile is found to depend not only on the magnitude but also the shape of the target plasma density for the TFTR tangential injection svistem.

A time-dependent transport code. TRA.NSP, 6,7 is used to calculate the electron production rate. employing a Monte Carlo calculation for the beam ions and neutrals. In this calculation. the measured time evolution of $T_{e, i}(r), n_{e}(r), Z_{e f f}(r)$, and wall recycling via $H_{\alpha}$ are used. The deuterium neutrals from the neutral beam produce electrons through several different processes. The code calculates electron production by the basic processes: electron-impact ionization, proton-impact ionization, and ionization and charge exchange processes with impurities. The ionization of the thermal neutrals produced by charge exchange beam deposition are also calculated. 8 A unique feature of TRA.NSP is the inclusion of beam deposition from interaction with other beam ions and calculation of the beam charge exchange recapture process. The important features of a beam species mix. beam divergence, and power profile across the beam source are accurately modeled in this calculation. The estimated error in the TR.A.NSP calculation of the local electron source rate due to the beams is $\pm 10 \%$. The uncertainty is largely due to Monte ('arlo numerical noise. TR.A.NP calculations can be performed with both the old $3,5,\left(\sigma_{1}\right)$ and new $1,2,\left(\sigma_{2}\right)$ tabulations of the atomic 
physics cross-sections for the same discharge and compared with the experiments. Multi-step ionization 9,10] (MSI), a process which effectively enhances the crosssections, is important in plasmas where the density is high. The effect of MSI processes was previously examined in the TFR 11 tokamak. There, the heatingbeam deposition was examined through shine-through measurements. In general, the measured shine-through power was less than the calculation with $\sigma_{1}$. When the MSl processes were included, the measured shine-through power was more than the calculation. At present, the MSI calculation is available only with $\sigma_{1}$ through the models of Refs. $[9]$ and $[10]$.

An increase in local electron density can be the result of changes in the electron particle source from either neutral beam deposition or recycling neutrals from the tokamak wall. At the center of the plasma, the electron density is least affected by wall recycling changes 12 ? during the initial period (the first $100 \mathrm{msec}$ ) of neutral beam injection. Thus. provided that the changes in the density can be measured with sufficient accuracy, the initial central density rise provides a good test of deposition calculation.

The deuterium plasmas studied had a wide range of parameters: the toroidal magnetic field $B_{T}$ was varied over the range 4-5 T, the plasma current $I_{P}$ over 1-2 MA, and the heating power $P_{b e}$ over 5-22 MW. In TFTR, twelve neutral beams inject tangentially, with six co-tangential to the plasma current and six counter-tangential. Deuterium neutral beams are injected with full energies of 90-110 kel. To reduce the effects of plasma rotation on the measured density or beam deposition, only discharges with nearly balanced momentum injection are studied, i.e., $\left(P_{c o}-P_{c t r}\right) /\left(P_{c o}-P_{c t r}\right) \leq$ 0.2 . where $P_{c o}$ and $P_{c t r}$ are the powers of the neutral beams injected co-parallel and counter-parallel to the plasma current, respectively.

The time-dependent electron density is calculated by inversion 13 of the measured line-integral density along 10 chords. The calculation takes into account the elongation of the magnetic flux surfaces (as inferred from poloidal field measurements 
(untside the plasma) and a self-consistent Shafranor shift. The absolute and relative uncertainties in the determination of local electron density are $=1.5$ and $0.5 \times 10^{18}$ $\mathrm{m}^{-3}$, respectively: These uncertainties are constant across the profile. 14 .

The calculated changes in electron density with $\sigma_{1}$ are compared to the measured values in Fig. 1. As shown in this figure, the initial rate of rise of the local electron density at small minor radii $(r / a \leq 0.5)$ can be entirely explained by beam fueling. In the outer region of the plasma $(r / a \geq 0 . \overline{5})$ the particle influx from the wall quickly dominates the particle source.

The best agreement with the measured central electron density rise is obtained using $\sigma_{1}$. Among $\sigma_{2}$ points, the hydrogen impact ionization cross-section is significantly smaller at low energies compared to those of $\sigma_{1}$ points. This results in the calculations predicting deeper penetration and significantly more on-axis deposition. The $\sigma_{2}$ for electron jonization and charge exchange processes are relatively close to the $\sigma_{1}$.

The difference between the calculated rise $\left(\Delta n_{e}(0)_{c a l}\right)$ in the central electron density for the neutral-beam particle source and the measured rise $\left(\Delta n_{e}(0)_{\text {meas }}\right)$ over the initial 100 msec, normalized to the measured value, is shown in Fig. 2. This difference is shown using $\sigma_{1}, \sigma_{1}$ with MSI processes, and $\sigma_{2}$. As expected. the effects of MSl processes and the differences in cross-sections are significant in plasmas with high density. ('alculations including MSI processes with the $\sigma_{2}$ should provide the best results for comparing to the experiments. The relative effect of MSI processes in the calculations with $\sigma_{2}$ are expected to be similar to those with $\sigma_{1}$. Since the XISI processes enhance the cross-sections, while the new hydrogen impact ionization crosssections are smaller, the effect of including the MSI processes and using $\sigma_{2}$ roughly cancel, and would be expected to result in agrecment with calculations just using $\sigma_{1}$.

To compare deposition calculations for a number of conditions it is convenient to 
define the deposition profile shape factor

$$
H_{n e}=\frac{S_{b e}(0, t)}{\left\langle S_{b e}(r, t)\right\rangle} .
$$

where $S_{b e}(0 . t)$ and $\left\{S_{b c}(r . t)\right\rangle$ are central and volume averaged electron source rate due to the neutral-beam. respectively. This definition is similar to the density peakedness factor $F_{n e} \cdots n_{e}(0) /\left\{n_{e}\right\rangle$, where $n_{e}(0)$ is the central electron density and $\left\langle n_{e}\right\rangle$ is volumeaveraged electron density.

The penetration of the heating-beam is expected to be an exponential function of electron density. The calculated $H_{n e}$ for a wide range of line-averaged densities $\left(\bar{n}_{e}\right)$ with relatively broad profile shapes $\left(F_{n e} \leq 2\right)$, can be described as

$$
H_{n e}=a \exp -b \bar{n}_{e}
$$

where $a$ and $b$ are appropriate coefficients. In a plasma with a low target density, the differences between using $\sigma_{1}$ or $\sigma_{2}$ in the calculation are relatively small and effects of MSI processes are not significant. As the target density is increased. the effects of MSI and differences due to cross-sections are pronounced, but go in different directions. The calculated $H_{n e}$, using $\sigma_{1}, \sigma_{1}$ with MSI processes, or $\sigma_{2}$ is fitted to Eq. (2) and the coefficients are evaluated. The ratio of the calculated $H_{n e}$ to the fitted $H_{n e}$ is illustrated in Fig. 3. Here, the averaging time for the calculation of $H_{n e}$ was 50 msec. For the TFTR plasmas. the e-folding values of $\bar{n}_{e}$ for $H_{n e}$ with the $\sigma_{2}$ and $\sigma_{1}$ are 3.8 and $3.0 \times 10^{19}, \mathrm{~m}^{3}$. respectively. Thus the calculated penetration depth varies by $\cong 30 \%$ due to the differences in atomic cross section tabulations. When the MSI processes are included in the calculation with $\sigma_{1}$, the penetration depth is reduced by $\simeq 20 \%$ and the corresponding e-folding value is $2.4 \times 10^{19} / \mathrm{m}^{3}$.

However. $H_{n e}$ for peaked profiles $\left(F_{n e} \geq 2\right)$ deviates significantly from the exponential dependence projected for the broad target profiles. Figure 4 shows the ratio between the calculated $H_{n t}$ for a variety of profile shapes and the fit ted $H_{n e}$, calculated with $\sigma_{1}$ in Fig. 3. The penetration depth for peaked density profiles is significantly enhanced compared to that for broad profiles as $\bar{n}_{e}$ is increased in TFTR plasmas. 
In neutral-beam heated tokamak plasmas, it is desirable to have a peaked deposition profile to optimize heating efficiency. A peaked $H_{n e}$, while not a sufficient condition. is helpful for improved energy confinement 15! in neutral-beam heated plasmas. In order to maintain a peaked $H_{n e}$ at high density, the density profile has be peaked.

In summary. the calculated neutral-beam deposition in a tokamak plasma is consistent with the measured central electron density rise over a wide range of plasma density and profile shape. Use of the older atomic physics cross-section tabulation gives the best agreement, as the effects of the new tabulation of cross-sections or including multi-step ionization processes appear to cancel even at high density for TFTR parameters. However. the new tabulation of atomic cross-sections together with MSI processes should be used in the calculation of neutral beam penetration in plasmas. The beam deposition profile shape is not only a function of line density but also a strong function of the target density profile shape in a tangential injection system like TFTR. Obtaining strongly peaked heating profiles requires low target density or highly peaked targets, preferably both.

\section{Acknowledgments}

The authors wish to acknowledge valuable discussions with Drs. S.D. Scott and J.L. (allen and the assistence of $K$. Phaneuf. The authors wish to thank the TFTK staff. the Neutral Beam Group who contributed to the completion of this work. This work was supported by L'S. Department of Energy contract No. DE-AC'O2-76-('HO3073. 


\section{References}

1) Shah. M.B., Elliott, D.S., Gilbody, H.B., J. Phỵs. B: At. Mol. Phỵs. 20 (1987) $2481-2485$.

2. Barnett. ('.F., ORNL-6086, Vol-1, Controlled Fusion Atomic Data Center. ()RNL, (July, 1990)

3 Rudd. M.E.. Kim. Y.K., Madison, D.H.. Gallagher, J.W., Rev. Mod. Phỵs. 57 (1985) 965.

4 Olson, R.E., Haselton, H.H., Phys. Rer. A 16 (1977) 531.

5 Riviere. A.C.., Nucl. Fusion 11 (1971) 363.

6 Hawryluk. R.... in Physics of Plasma Close to Thermonuclear Conditions, edited by ('oppi, B., et al. (Commission of the European Communities, Brussels, 1980), Vol. 1. p. 19.

7) Goldston, R.J., McCune, D.C., Towner, H.H., et al., Comput. Phys. 43 (1981) 61.

8: Tamor. S.J., ('ompt. Phỵs. 40 (1981) 104.

9 Boley. ('D.. Janev, K.K.. Pust. I).E., Phys. Rev. Lett. 52 (1984) 534.

10) Janer, K.K., B̈uley. ('.D.. Post, D.E., Nucl. Fusion 29 (1989) 2125.

11. Equipe TFR, Plasma Phỵs. Controlled Fusion 29 (1986) 37.

12. Mansfield. D.K.. Efthimion. P.C., Hulse, R.A.. et al., in Plasma Phỵs. ('ontrolled Fusion. Vol. 11D. Part 1, European Physical Society. Meeting, Madrid (198i) 314.

13. Park. H.K.. Plasma Phỵs. Controlled Fusion 31 (1989) 2035.

14. Park. H.K.. Rev. Sci. Instrum. 61 (1990) 2879. 
15 Callen, J.D. C'hristiansen. J.P., C'ordey. J.C... et al.. Nucl. Fusion 27 (198T) 1857. 


\section{Figures}

Fig. 1. A comparison between the measured electron density and the calculated electron source from the neutral beams for several different radii. The target plasma has a low line-averaged density $\left(\bar{n}_{e}=0.8 \times 10^{19} \mathrm{~m}^{-3}\right)$, and $I_{P}=1.4 \mathrm{MA}, B_{T}=4 \mathrm{~T}$. $P_{t *}=14 \mathrm{MW}$ and $a=0.9 \mathrm{~m}$. The histograms represent the integral of the calculated $S_{b e}(r, t)$ from the start of beam injection at $4.0 \mathrm{sec}$.

Fig. 2. The normalized difference between calculated and measured initial central electron density rise is shown as a function of target plasma density for 6 different discharges. calculated with the three different methods: $\sqsubset-$ with $\sigma_{2}$. ० - with $\sigma_{1}$. and filled $\sqsubset$ - with $\sigma_{1}$ and MSI processes. The time averaging was $100 \mathrm{msec}$ and plasma parameters are as follow; $B_{T}$ ranges over $4.5 \mathrm{~T}, I_{F}$, over $1.2 \mathrm{MA}$, and $P_{b e}$ over 10-22 $\mathrm{MM}$.

Fig. 3. The ratio between the calculated and fitted $H_{n e}$ is shown as a function of $\bar{n}_{e}$ for the broad target density profiles $\left(F_{n e} \leq 2\right), H_{n e}$ is calculated by the three different methods: the symbols are the same as in Fig. 2 and each data set has then been fit separately. For the fitted da a calculated with $\sigma_{2}, \mathrm{a}=4.67$ and $\mathrm{b}=$ $0.26 \mathrm{~m}^{-3}$. For the fitted data calculated with $\sigma_{1}$, $a=4.76$ and $b=0.33 \mathrm{~m}^{-3}$. For the fitted data calculated with $\sigma_{1}$ together with MSI processes. $a=5.27$ and $\mathrm{b}=$ $0.41 m^{3}$.

Fig. 4. The enhanced penetration of the heating-beam due to effects of the target density profile shape are illustrated. The ratio between the calculated $H_{n e}$ for a variety of target density profile shapes and the fitted $H_{n e}$, calculated with the $\sigma_{1}$ for the broad profile shapes is depicted as a function of $n_{e}$. Filled $-F_{n e} \leq 2.0$ $-2.0 \leq F_{n e} \leq 2.5 . \Delta-2.5 \leq F_{n e} \leq 3.0$. and filled $\circ-F_{n e}>3.0$. 


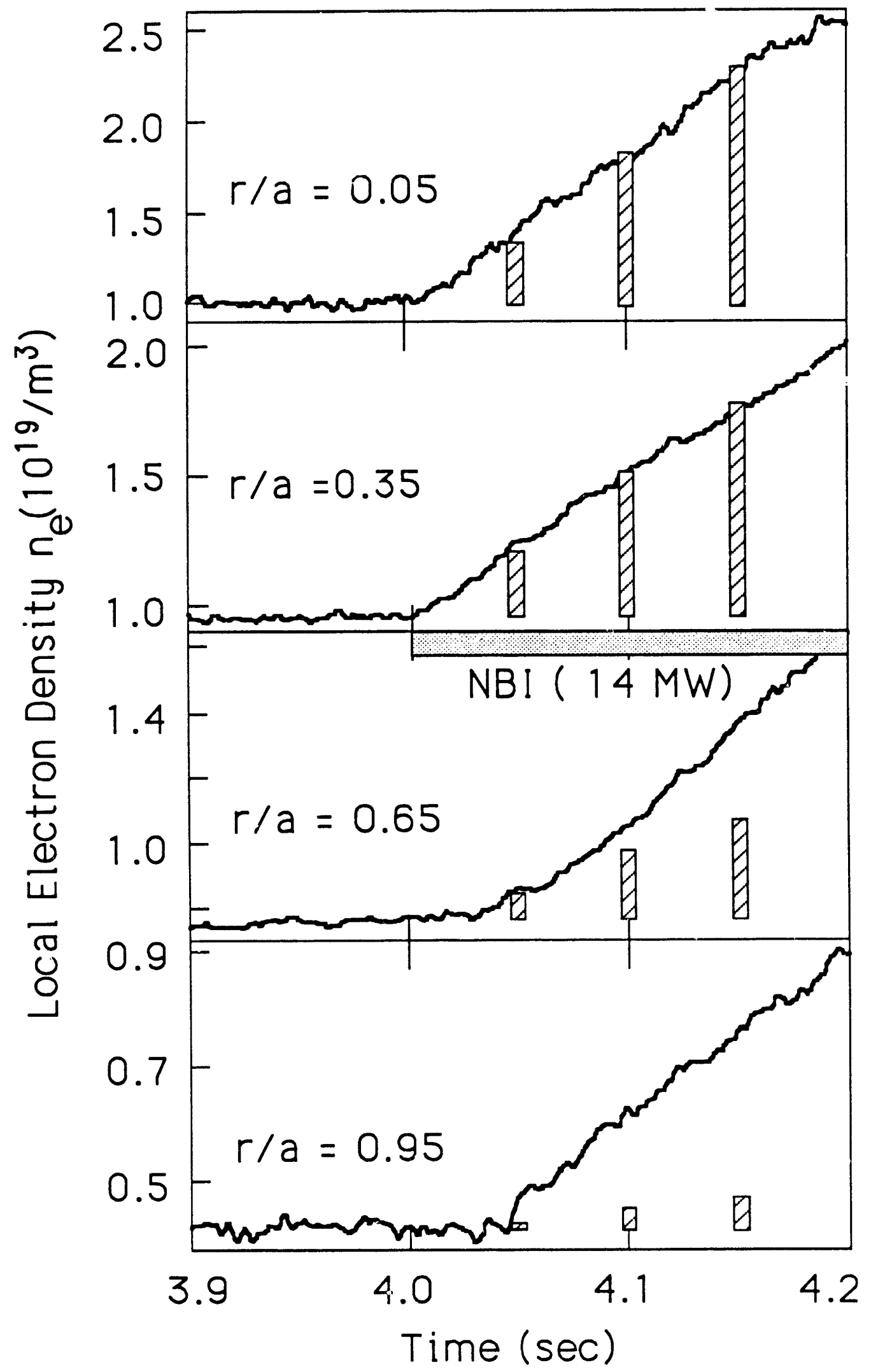

Fig. 1 


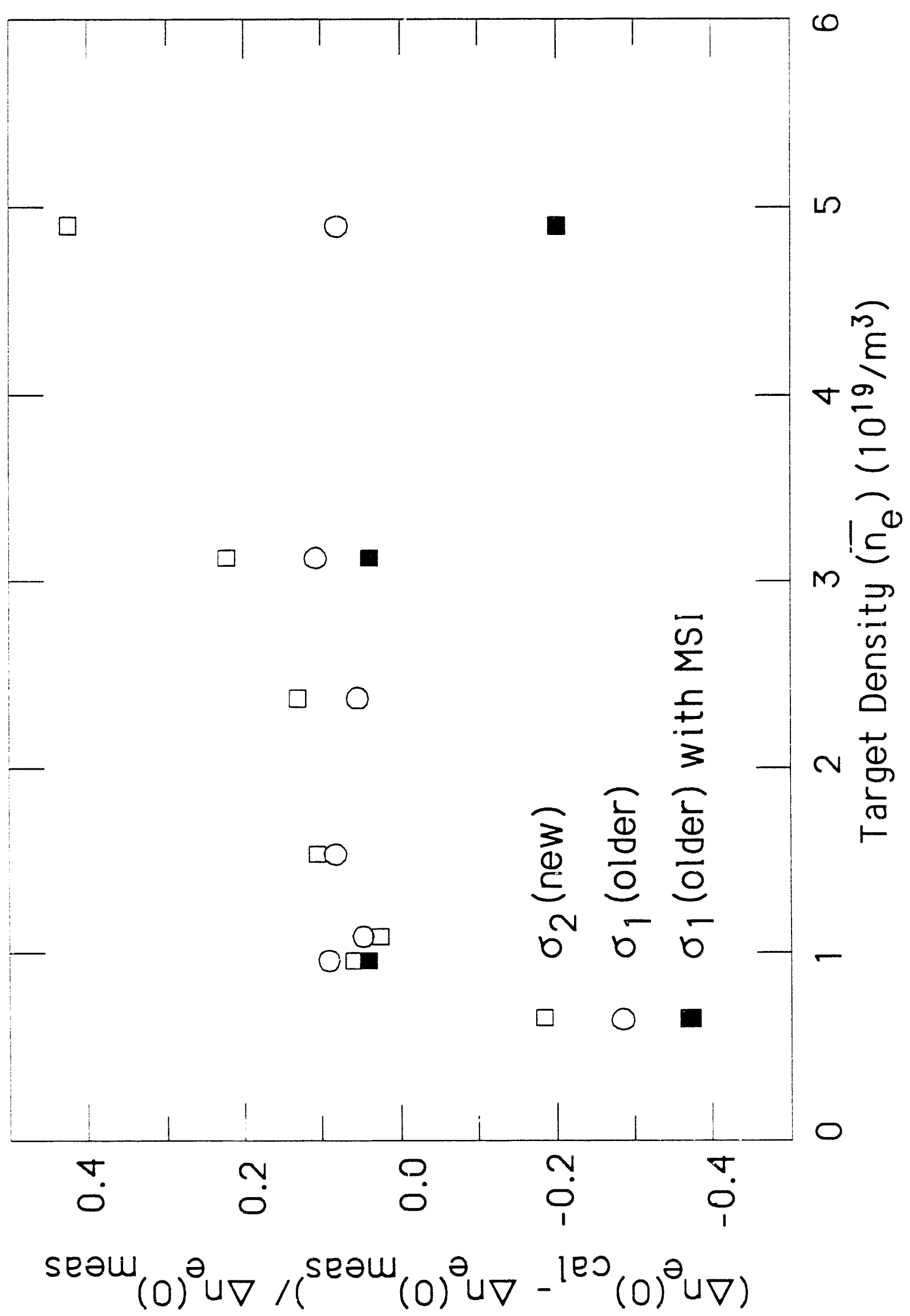

Fig. 2 


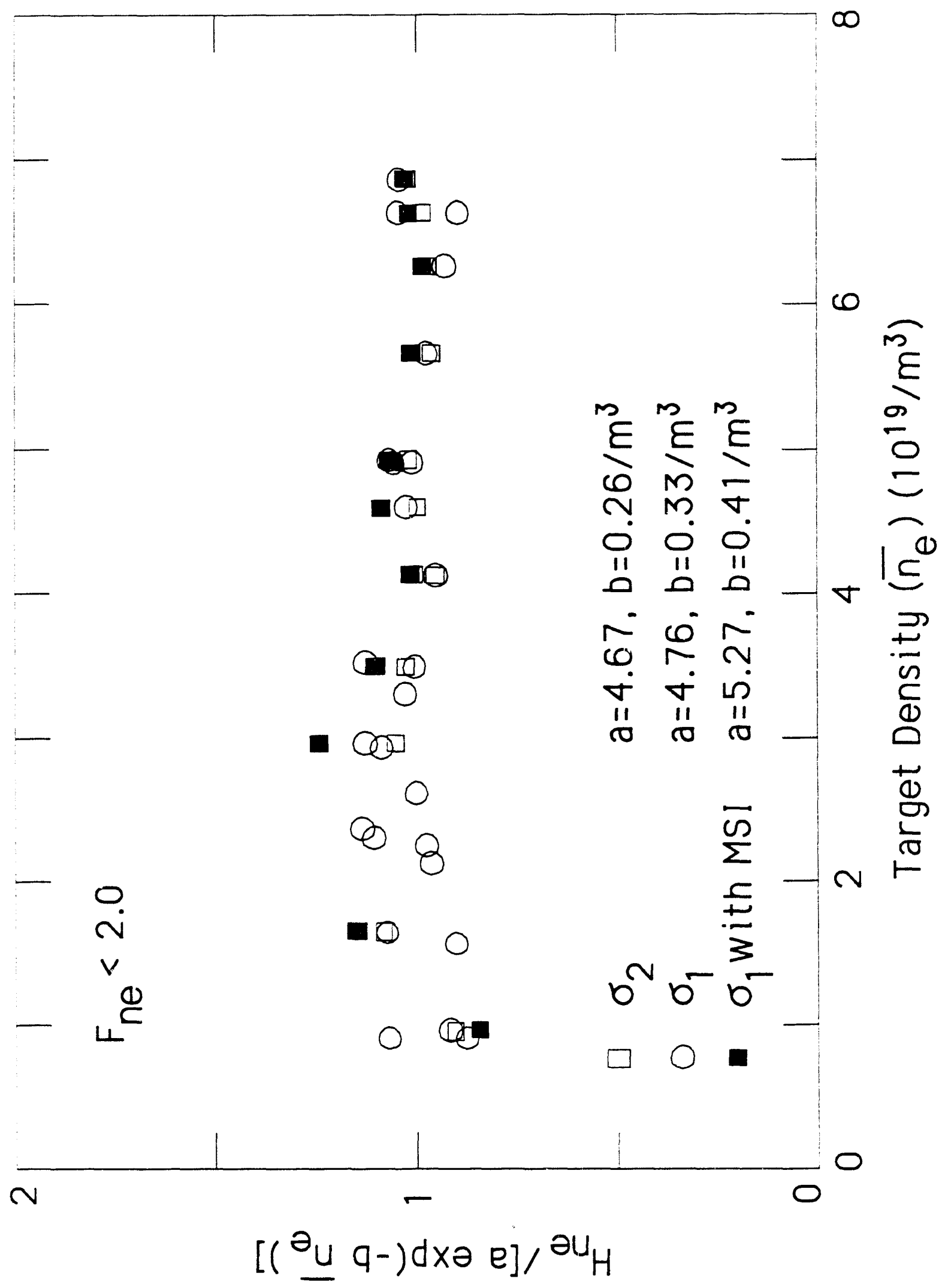

Fig. 3 


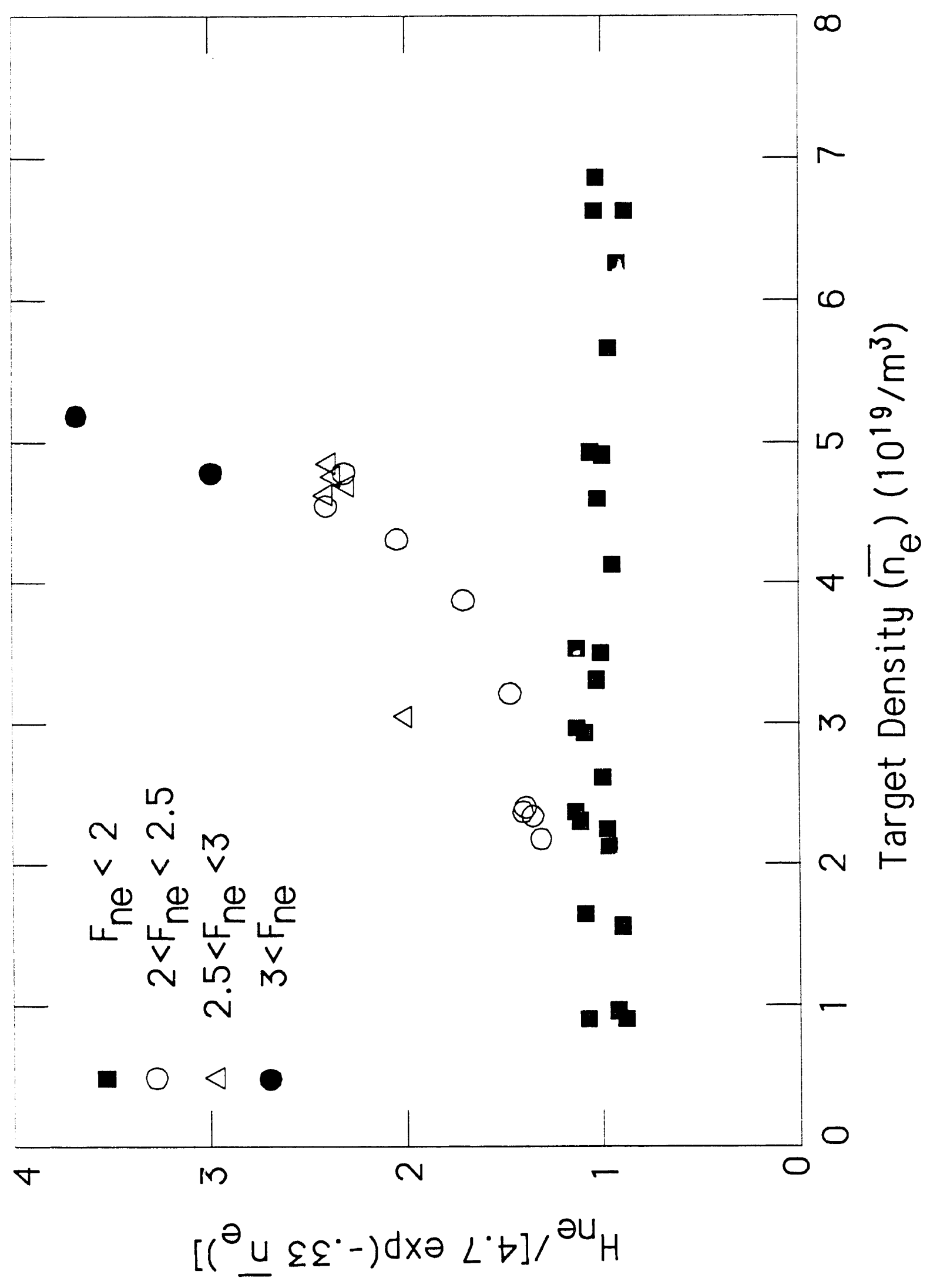

Fig. 4 


\section{EXTERNAL DISTRIBUTION IN ADDITION TO UC -420}

Dr. F. Paoloni, Univ. of Wollongong. AUSTRALIA

Prof. M.H. Brennan. Univ. of Sydney, AUSTRALIA

Plasma Research Lab., Australian Nat. Univ., AUSTRALIA

Prof. I.R. Jones, Flinders Univ, AUSTRALIA

Prof. F. Cap. Inst. for Theoretical Physics, AUSTRIA

Prof. M. Heindler, Institut fur Theoretische Physik, AUSTRIA

Prof. M. Goossens, Astronomisch InstituUt, BELGIUNe

Ecole Royale Militaire, Lab. de Phy. Plasmas, BELGIUM

Commission-European, DG. XII-Fusion Prog., BELGIUM

Prof. R. Bouciquie, Rijksuniversiteit Gent. BELGIUM

Dr. P.H. Sakanaka, Instituto Fisica, BRAZIL

Instituto De Pesquisas Espaciais-INPE, BRAZIL

Documents Office, Atomic Energy of Canada Lto., CANADA

Dr. M.P. Bachynski, MPB Technologies, Inc., CANADA

Dr. H.M. Skarsgard, Univ. of Saskatchowan, CANADA

Prof. J. Teichmann, Univ. of Montreal, CANADA

Prof. S.R. Sreenivasan, Univ. of Calgary, CANADA

Prof. T.W. Johnston, INRS-Energie, CANADA

Dr. R. Bolton. Centre canadien de husion magnétique, CANADA

Dr. C.R. James, Univ. of Alberta, CANADA

Dr. P. Lukac, Komenskoho Universzita, CZECHOSLOVAKIA

The Librarian, Culhem Laboratory, ENGLAND

Library, RS1, Rutherford Appleton Laboratory, ENGLAND

Mrs. S.A. Hutchinson, JET Library, ENGLAND

P. Mahonen, Univ. of Helsinkj, FINLAND

C. Mouttet, Lab. de Physique des Milieux lonisés, FRANCE

J. Radet, CEN/CADARACHE - Bat 506, FRANCE

Ms. C. Rinni, Univ. of loannina, GREECE

Dr. T. Mual, Acedemy Bibliographic Ser, HONG KONG

Preprint Library, Hungarian Academy of Sci., HUNGARY

Dr. B. Das Gupta, Saha inst. of Nuclear Physics, INDIA

Dr. P. Kaw, Inst. for Plasma Research, INDIA

Dr. P. Rosenau, Israel Inst. of Technology, ISRAEL

Librarian, Intemational Center for Theo Physics, ITALY

Miss C. De Palo, Associazione EURATOM-ENEA, ITALY

Dr. G. Grosso, Istituto di Fisica del Plasma, ITALY

Dr. H. Yamato, Toshiba Res \& Devel Center, JAPAN

Prof. I. Kawakami, Atomic Energy Res.Inst., JAPAN

Prof. K. Nishikawa, Hiroshima Univ., JAPAN
Director, Japan Atomic Energy Research Inst.. JAPAN

Prof. S. Itoh. Kyushu Univ., JAPAN

Data and Planning Center, Nagoya Univ., JAPAN

Prof. S. Tanaka, Kyoto Univ., JAPAN

Library, Kyoto Univ., JAPAN

Prof. N. Inoue. Univ. of Tokyo, JAPAN

S. Mori, Technical Advisor, JAERI, JAPAN

O. Mitarai, Kumamoto Inst. of Technology, JAPAN

H. Jeong, Korea Advanced Energy Research Inst., KOREA Prof. D.I. Choi. The Korea Adv. Inst. of Sa. Tech., KOREA

Prof. B.S. Liley, Univ. of Waikato, NEW ZEALAND Inst. of Plasma Physics, PEOPLE'S REPUBLIC OF CHINA Librarian, Inst. of Physics, PEOPLE'S REPUBLIC OF CHINA Library, Tsinghua Univ., PEOPLE'S REPUBLIC OF CHINA Z. L. S.W. Inst Physics, PEOPLE'S REPUBLIC OF CHINA Prof. J.A.C. Cabral, Instituto Superior Tecnico, PORTUGAL Dr. O. Petrus, AL I cuza Univ., ROMANIA Dr. J. de Villiers, Fusion Sudies, AEC, S. AFRICA Prof. M.A. Hellberg, Univ. of Natal, S. AFRICA C.I.E.M.A.T, Fusion Division Library, SPAIN Dr. L Stonflo. Univ. of UMEA, SWEDEN Library, Royal inst. of Technology. SWEDEN Prof. H. Wilhelmson, Chalmers Univ. of Tech., SWEDEN Centre Phys. Des Plasmas, Ecole Polytoch, SWITZERLAivo Bibliotheok, Inst. Voor Plasma-Fysica, THE NETHERLANDS M. Durgut, Vico Chairman, Middle East Tech. Univ., TURKEY Dr. D.D. Ryutov, Siberian Branch of Academy of Sci., USSR Dr. G.A. Eliseev, Kurchatov Inst., USSR Librarian, The Ukr.SSR Acaderny of Sciences, USSR Dr. L.M. Kovrizhnykh, Inst of General Physics, USSR Kemforschungsanlage GmbH. Zentralbibliothek, W. GERMANY Bibliothek, Inst. Für Plasmaforschung, W. GERMANY Prof. K. Schindler, Ruhr-Universitát Bochum, W. GERMANY Dr. F. Wagner, (ASDEX), Max-Planck-Institut, W. GERMANY Librarian, Max-Planck-Institut, W. GERMANY Prof. R.K. Janev, Inst. of Physics, YUgosLAVIA 

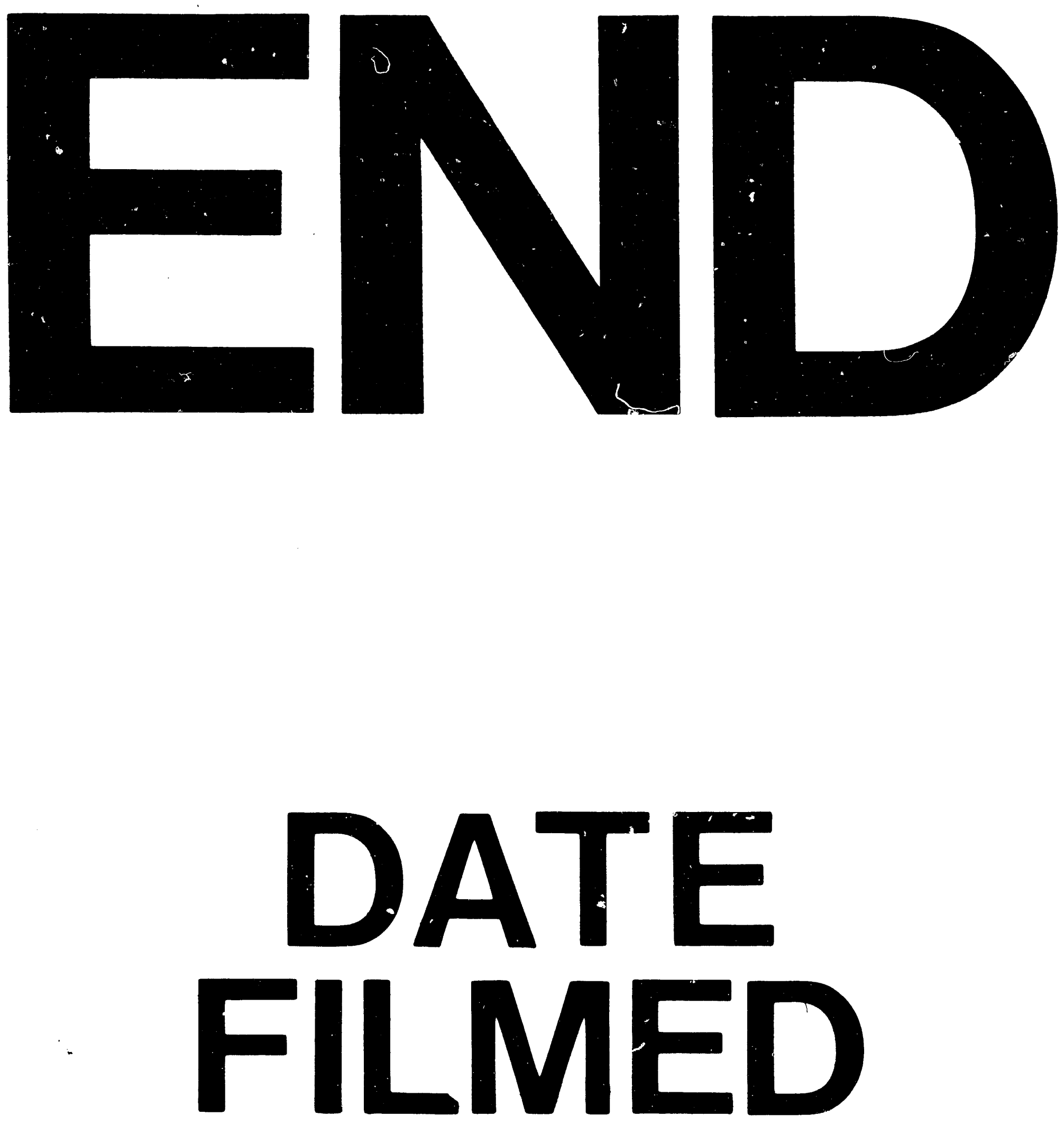

$t$

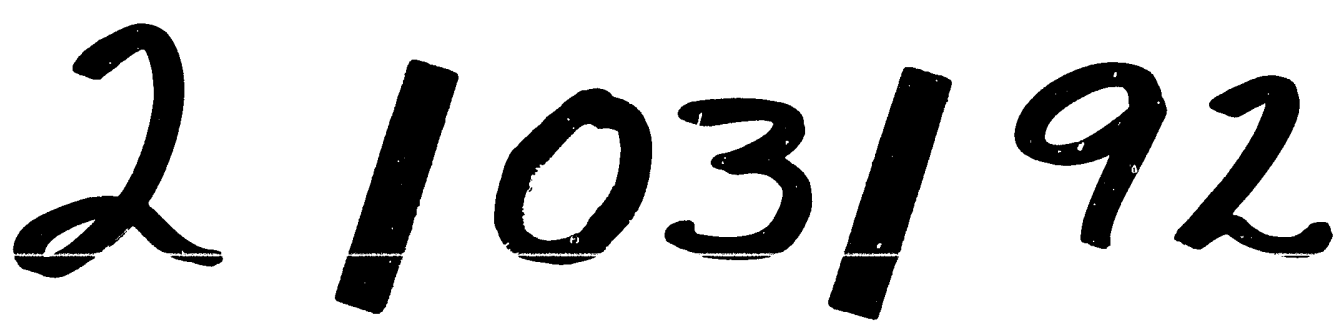


